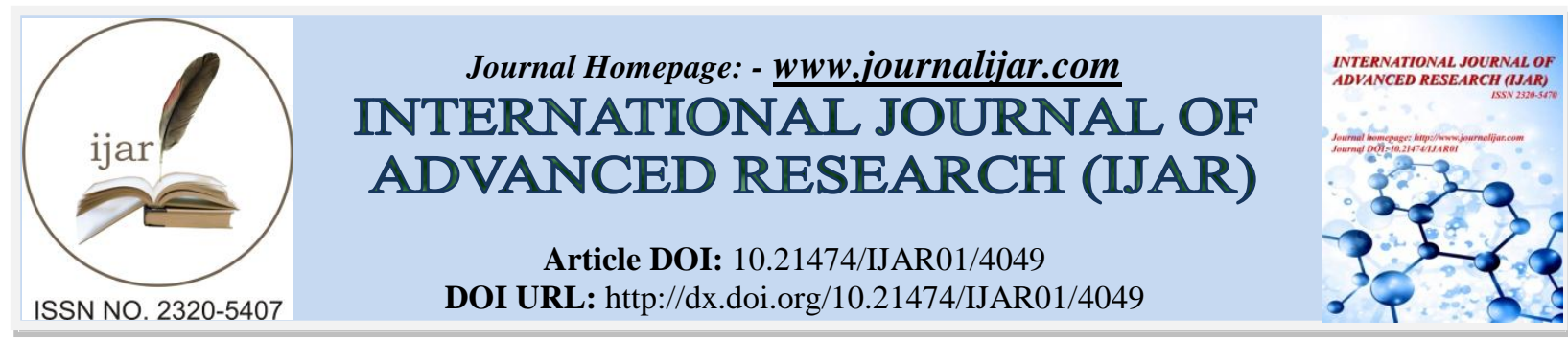

RESEARCH ARTICLE

\title{
PHENOL ADSORPTION USING ACTIVATED CARBON PREPARED FROM DEGRADATION OF INDUSTRIAL WASTE LIGNIN.
}

\section{R. A. Nandanwar ${ }^{1}$, A. R. Chaudhari ${ }^{1}$ and J. D. Ekhe ${ }^{2}$.}

1. Priyadarshini Bhagwati College of Engineering,Nagpur, Maharashtra, India.

2. Visveswaraya National Institute of Technollogy, Nagpur, Maharashtra, India.

\section{Manuscript Info}

Manuscript History

Received: 26 February 2017

Final Accepted: 24 March 2017

Published: April 2017

Key words:-

Lignin, thermal degradation, activated carbon, adsorption

\begin{abstract}
Phenol and phenolic compounds are the common water pollutants in the effluents from various industries and even in the small amounts are undesirable for human health. In this research work adsorption of phenol on the activated carbon prepared from thermal degradation of industrial waste lignin was studied. The industrial waste lignin was subjected to thermal degradation at temperature of $500^{\circ} \mathrm{C}$ in $\mathrm{N}_{2}$ atmosphere in presence of $\mathrm{ZnCl}_{2}$ catalyst. The major product obtained after degradation is the activated carbon. The activated carbon obtained was characterized with proximate analysis, CHN analysis, FTIR, SEM and surface textural properties. The surface morphology of the AC reveals that it posses high porosity and surface area, hence it can be utilized for adsorption purpose. The adsorption capacity of the prepared AC for phenol was studied with various parameters such as effect of contact time, adsorbent dose, $\mathrm{pH}$ and initial concentration. The maximum adsorption for phenol is found to be $19.3050 \mathrm{mg} / \mathrm{g}$. To describe the equilibrium isotherms, Langmuir and Freundlich models were applied. Although adsorption equilibrium data was found to follow Freundlich model, it was better fitted in Langmuir model. The scope of this work suggests that the AC obtained from industrial waste lignin can be utilized as a low cost adsorbent for the removal of phenol from aqueous solution.
\end{abstract}

Copy Right, IJAR, 2017,. All rights reserved.

\section{Introduction:-}

Phenol and phenolic compounds are common contaminants in the effluents from industries such as plastics, leather, paint, textile and petrochemical[1]. Such contaminated water in human body causes protein degeneration, tissue erosion, paralysis of central nervous system and the repeated exposure to low levels of phenol in water causes health effects such as damage to liver, kidney and pancreas[2]. Also, phenol is a strong eye and respiratory irritants. Phenolic compounds are harmful to organism at low concentrations and many of them have been classified as hazardous pollutants[3]. As phenol and phenolic compounds are harmful, there is a need for its removal in order to prevent the environmental pollution. The commonly used methods for the treatment of aqueous solutions containing phenol includes stripping, solvent extraction, oxidation, ion exchange, biodegradation and adsorption[4]. Among these, adsorption onto the activated carbon is the most widely used method for the removal of dissolved organics from waters. 
In order to scavenge organic species like phenol from aqueous solutions, activated carbon could be one of the potential adsorbent. Activated carbon [5-6] is the commonly used adsorbent for removal of dyes and phenolic compounds. Activated carbons are the amorphous form of carbon characterized by high surface areas, micropore volumes, large adsorption capacities, fast adsorption kinetics and relative ease of regeneration [7] It has wide applications like removal of organic, inorganic pollutants from drinking water and as catalyst support. Adsorption capacity of activated carbon mainly depends on its porosity and surface area. The textural property of activated carbon depends on the method of preparation and starting material [8]. However commercially available activated carbons are very expensive. Therefore there is a need to produce low cost and effective carbons for water pollution control.

Recently a lot of work has been published on the production of AC by using agricultural waste products such as onion skin, flour waste, paddy husk, paddy straw, waste slurry[9,10], fly ash[11], lignite[12], pine bark, peat and lignin [13-20] etc for adsorption studies. Some researchers have reviewed the application of low-cost adsorbents for removal of organic compound like phenol from contaminated waters [21,22]. Researcher's interest is growing in use of other low cost and abundantly available lingo-cellulosic material as a precursor for the preparation of activated carbon [23].

Pulp and paper industries uses enormous quantity of wood material and the lignin thus removed is considered as a recurring waste material in huge quantities and its disposal is a matter of environmental concern. A considerable research work has been reported for its partial utilization e.g. hydrogenation, alkali fusion, polymer blending, wood adhesive, carbon fibers etc. As lignin is a three dimensional branched polymer with aromatic phenolic units, it degrades slowly and leads to the formation of a carbonaceous residue as a major degradation product. Thus one of the potential applications of lignin is as a precursor for the preparation of activated carbon. The surface textural properties and morphology of the activated carbon produced depends upon the various reaction conditions. The chemical activation enhances the surface characteristics of the activated carbon.

In the present research work, the industrial waste lignin was subjected to high energy degradation in $\mathrm{N}_{2}$ atmosphere with chemical activating agent $\left(\mathrm{ZnCl}_{2}\right)$. The pyrocatalytic degradation has produced the activated carbon with high surface area. Therefore the activated carbon obtained from thermal degradation of industrial waste lignin has been used for the adsorption studies of Phenol.

\section{Materials and Method:-}

Adsorbent:-

In this present work, the kraft lignin used has been procured in the form of black liquor from Simplex Paper Mills, Gondia, Maharashtra. The solid lignin was precipitated from black liquor by acidification with dilute $\mathrm{HCl}$ and then purified. The pyrocatalytic degradation of pure lignin was carried out in presence of activating agent $\mathrm{ZnCl}_{2}$.

\section{Preparation of Activated Carbon:-}

$80 \mathrm{~g}$ of pure lignin is impregnated with $80 \mathrm{~g}$ of $\mathrm{ZnCl}_{2}$ in $250 \mathrm{ml}$ round bottom flask along with thermocouple, distilling head and condensers in $\mathrm{N}_{2}$ atmosphere at $500^{\circ} \mathrm{C}$. It was heated strongly for 5 hrs. At the bottom of the flask, a carbonaceous residue (activated carbon) was left. After cooling, it was scratched out from the flask and the $\mathrm{AC}$ obtained was crushed and sieved to get a particle size of 300 microns. Then it was washed with dilute $\mathrm{HCl}$ several times followed by plenty of distilled water to remove any traces of $\mathrm{ZnCl}_{2}$ used during thermal degradation. The AC weighed $46.60 \mathrm{~g}$.

\section{Adsorbate:-}

The stock solution of Phenol concentration $1000 \mathrm{mg} / \mathrm{l}$ was prepared. The concentration of phenol in solutions was determined spectrophotometrically at $270 \mathrm{~nm}$. Different concentration of phenol solutions were prepared ranging from 100 to $200 \mathrm{mg} / \mathrm{l}$ from its stock solution.

Characterization of pure lignin and the Activated Carbon obtained from thermal degradation of lignin in $\mathbf{N}_{2}$ atmosphere in presence of $\mathrm{ZnCl}_{2:-}$

Proximate Analysis:-

Proximate analysis of pure lignin and the AC obtained by thermal degradation was carried out by standard method to find out the percentage of moisture, volatile matter, ash and fixed carbon. 


\section{CHN (Elemental )Analysis:-}

The elemental analysis of pure lignin and the prepared AC was carried to find out the percentage of carbon, hydrogen and nitrogen present. The Elemental Analyzer (Carlo Erba Model 1108) was used for the analysis. The \% of oxygen was calculated by difference.

\section{FTIR Analysis:-}

The Infra Red Spectrum of pure lignin and the AC obtained from thermal degradation of lignin in $\mathrm{N}_{2}$ atmosphere has been recorded by using FTIR-Schimadzu 100 and Perkin Elmer using KBr pellets. The spectra were compared according to the assignments [24,25] given to the peaks so as to see the structural changes occurred in lignin during thermal degradation.

\section{SEM Analysis:-}

The surface morphology of lignin and the AC obtained from thermal degradation of lignin was studied by SEM. The SEM images were recorded with Scanning Electron Microscope (JEOL; JSM-6380A) equipped with an electron probe analyzer system (accelerating voltage $30 \mathrm{KV}$ ). The sample was coated with palladium in order to have good conductivity.

\section{Surface Textural properties:-}

Specific surface area (textural properties) of the prepared AC was determined at $77^{\circ} \mathrm{K}$ from nitrogen adsorption experiment conducted on Smart Sorb 93 Surface area analyzer. The sample was duly degassed at $300^{\circ} \mathrm{C}$ for $2 \mathrm{hrs}$ under vacuum prior to its surface characterization. Then the sample was dipped in liquid nitrogen having temperature $\left(-196^{\circ} \mathrm{C}\right)$. In this flow, gas gets adsorbed on the surface and forms a monolayer on the surface. The adsorbed nitrogen is allowed to desorb by bringing the samples at room temperature. The desorbed nitrogen is proportional to the surface area and so measured to calculate surface area.

Optimization of various parameters for maximum uptake of Phenol on the Activated Carbon obtained by thermal degradation of lignin:-

\section{Optimization of adsorbent dose:-}

To optimize the adsorbent dose for maximum uptake, studies were carried out for uptake of phenol on the AC. $0.25 \mathrm{~g}, 0.5 \mathrm{~g}, 0.75 \mathrm{~g}, 1 \mathrm{~g}, 1.25 \mathrm{~g}, 1.5 \mathrm{~g}$ and $2 \mathrm{~g}$ of AC were agitated with $100 \mathrm{ml}$ phenol solution for 60 minutes separately with intermittent stirring. The solutions were filtered and phenol concentrations in aqueous solutions were determined by measuring the absorbance at $269.4 \mathrm{~nm}$ using UV visible spectrophotometer. (See Table 3).

\section{Optimization of pH:-}

To select the $\mathrm{pH}$ range for maximum uptake, studies were carried out for phenol at different $\mathrm{pH}$ ranging from 2-10. $1 \mathrm{~g}$ of the $\mathrm{AC}$ was agitated with $100 \mathrm{ml}$ of phenol solution maintained at different $\mathrm{pH}$ range for 60 minutes with intermittent stirring. The solutions were filtered and the phenol concentrations in aqueous solutions were determined by using UV visible spectrophotometer. (See Table 4).

\section{Optimization of contact time:-}

To optimize the contact time for maximum uptake, adsorption studies were carried out for phenol at different contact time from $1 \mathrm{hr}$ to $6 \mathrm{hrs}$. $1 \mathrm{~g}$ of $\mathrm{AC}$ was agitated with $100 \mathrm{ml}$ of phenol solution for different contact time with intermittent stirring. The solutions were filtered and the phenol concentrations in aqueous solutions were determined by using UV visible spectrophotometer (See Table 5).

\section{Adsorption experiments of Phenol:-}

Adsorption isotherms of phenol were obtained using the adsorbent. These adsorption isotherms were used to determine the maximum adsorption capacity of the $\mathrm{AC}$ obtained from thermal degradation of lignin. Batch adsorption experiments were performed using phenol with different initial concentration ranging from $100 \mathrm{mg} / \mathrm{l}$ to $200 \mathrm{mg} / \mathrm{l}$. Adsorption studies were performed by shaking a fixed mass of adsorbent $(1 \mathrm{~g})$ in fixed volume of phenol solution $(100 \mathrm{ml})$ separately for $3 \mathrm{hrs}$. These experiments were performed at $\mathrm{pH} 7$. 
Adsorption capacity of adsorbent for Phenol $\left(\mathrm{q}_{\mathrm{e}}, \mathrm{mg} / \mathrm{g}\right)$ was calculated by mass balance

$$
q_{e}=\frac{\left(C_{0}-C_{e}\right) V}{m}
$$

where, $\mathrm{C}_{\mathrm{o}}$ and $\mathrm{C}_{\mathrm{e}}$ is the initial and final concentration of phenol in solution(mg/l), $\mathrm{V}$ is the volume(l) of phenol solution for adsorption experiments and $\mathrm{m}$ is the adsorbent mass $(\mathrm{g})$ respectively.

\section{Results and Discussion:-}

Characterization of pure lignin and the Activated Carbon obtained from thermal degradation of lignin in $\mathrm{N}_{2}$ atmosphere in presence of $\mathrm{ZnCl}_{2}$.

Proximate Analysis:-

Proximate analysis of pure lignin and the prepared AC shows difference in percentage of moisture, volatile matter, ash and fixed carbon. The results showed that the percentage of fixed carbon is high in the AC obtained in presence of $\mathrm{ZnCl}_{2}$ as compared to pure lignin.

Table 1:- Proximate analysis of lignin and prepared Activated Carbon (with $\mathrm{ZnCl}_{2}$ catalyst)

\begin{tabular}{|l|l|l|l|l|}
\hline \multirow{2}{*}{ Sample } & \multicolumn{3}{l}{} \\
\cline { 3 - 6 } & Moisture & Volatile Matter & Ash & Fixed Carbon \\
\hline Pure lignin & 4.20 & 42.68 & 9.02 & 44.10 \\
\hline $\begin{array}{l}\text { Activated } \\
(\text { Lignin+ZnCl }\end{array}$ Carbon & 1.98 & 22.8 & 15.13 & 60.08 \\
\hline
\end{tabular}

\section{CHN (Elemental) Analysis:l-}

The elemental analysis of pure lignin and the prepared AC was carried out. Higher carbon content in the prepared $\mathrm{AC}$ indicates that aromatic structure becomes dominant after degradation in the presence of catalyst used. It can be explained as, due to thermal degradation, the organic substances have degraded into volatile gases, liquid tar and the solid carbonaceous residue left behind with high carbon content. However, the low hydrogen and low oxygen content in AC may be due to breaking of molecular chain.

Table 2:- Elemental analysis of lignin and prepared Activated Carbon (with $\mathbf{Z n C l}_{\mathbf{2}}$ catalyst)

\begin{tabular}{|l|l|l|l|l|}
\hline \multirow{2}{*}{ Sample } & \multicolumn{2}{|l|}{ Elemental analysis (\%) } & Nitrogen & $\begin{array}{l}\text { Oxygen } \\
\text { (arithmetically) }\end{array}$ \\
\cline { 3 - 6 } & Carbon & Hydrogen & 0.1 & 32.8 \\
\hline Pure lignin & 58.9 & 8.2 & 0 & 27.59 \\
\hline $\begin{array}{l}\text { Activated Carbon } \\
\left(\text { Lignin+ }+\mathrm{ZnCl}_{2}\right)\end{array}$ & 69.11 & 3.3 & & \\
\hline
\end{tabular}

\section{FTIR Analysis:-}

During thermal degradation, the changes occured in lignin were assessed through IR studies. These studies of AC showed the structural changes occurred during the thermal treatments. The comparative study of IR showed almost flattening of maximum peaks in the AC obtained on thermal degradation of lignin. After carbonization, all the peaks related to $\mathrm{C}-\mathrm{OH}, \mathrm{CH}, \mathrm{CH}_{2}, \mathrm{CH}_{3}, \mathrm{CO}$ and $\mathrm{C}=\mathrm{O}$ groups were considerably reduced in the prepared $\mathrm{AC}$.

Fig.1. shows the FTIR spectra of pure lignin, the first peak at $3413.44 \mathrm{~cm}^{-1}$ is assigned to OH stretching vibration of hydroxyl group of the lignin. A symmetric stretch for $\mathrm{CH}_{3}$ of methoxyl group appeared at $2840 \mathrm{~cm}^{-1}$. The absorbance at $2927.39 \mathrm{~cm}^{-1}$ arises from $\mathrm{C}-\mathrm{H}$ stretching in methyl and methylene group. A peak at $1713.83 \mathrm{~cm}^{-1}$ assigned to carbonyl stretching-unconjugated ketone and carboxyl groups. The peak at $1508.81 \mathrm{~cm}^{-1}, 1458.39 \mathrm{~cm}^{-1}$ and 1426.41 $\mathrm{cm}^{-1}$ corresponds to aromatic skeletal vibrations, $\beta-\mathrm{O}-4$ ether bond band at $1119.78 \mathrm{~cm}^{-1}$, Carbonyl stretching at $1713.83 \mathrm{~cm}^{-1}$. A small peak at $1035 \mathrm{~cm}^{-1}$ may be due to aromatic $\mathrm{CH}$ in plane deformation, guaiacyl type and $\mathrm{C}-\mathrm{O}$ stretching for primary alcohol. 


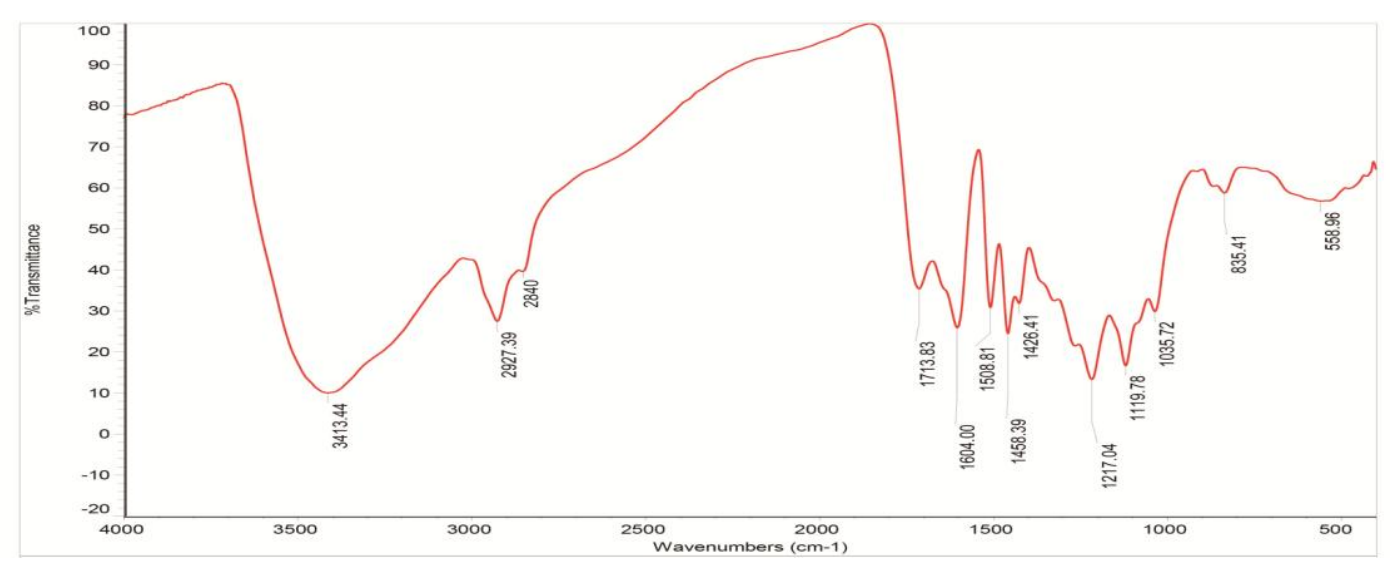

Figure 1:- FTIR spectra of pure lignin.

Fig.2. shows the FTIR spectra of activated carbon obtained from thermal degradation of lignin with $\mathrm{ZnCl}_{2}$ catalyst. The FTIR spectra for this AC showed the peak at $3426.71 \mathrm{~cm}^{-1}$ mainly due to $-\mathrm{OH}$ stretching and the peak at $1615.73 \mathrm{~cm}^{-1}$ resulting from $\mathrm{C}=\mathrm{C}$ stretching vibration in aromatic ring. A new peak at $1064 \mathrm{~cm}^{-1}$ may be due to the superposition of signals corresponding to oxygen functional groups like ether, phenol and lactones. For this AC, low absorption occurred in the region $800-1000 \mathrm{~cm}^{-1}$ suggests a lower content of substituted aliphatic groups on the aromatic ring. .

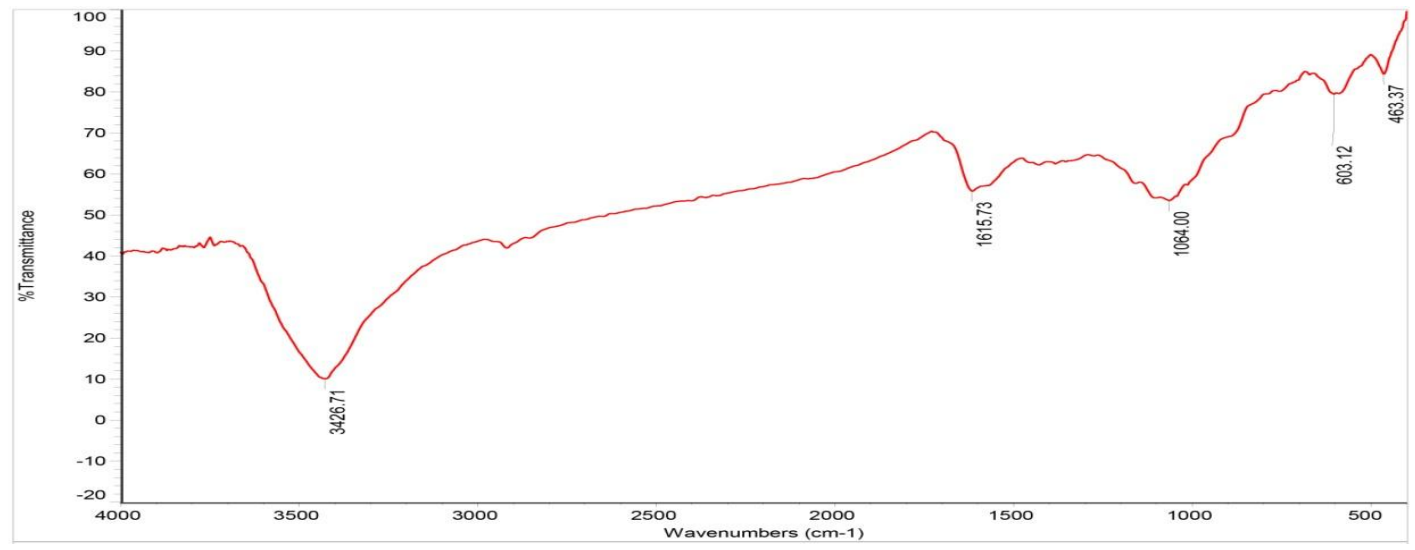

Figure 2:- FTIR spectra of $\mathrm{AC}$ from lignin with $\mathrm{ZnCl}_{2}$ catalyst.

From the above results, lignin and AC prepared from lignin in presence of catalyst showed a shift in wave numbers. The intensity of the transmittance due to hydrogen bonded $\mathrm{OH}$ stretching has been decreased in the $\mathrm{AC}$ as compared to pure lignin. The decrease may be due to the loss of phenolic or alcoholic groups during degradation. The peak due to symmetric $\mathrm{CH}_{3}$ stretch of $\mathrm{O}-\mathrm{CH}_{3}$ groups appeared at $2840 \mathrm{~cm}^{-1}$ in pure lignin disappeared from $\mathrm{AC}$, this shows that $\mathrm{CH}_{3}$ groups were removed from substituted aromatic ring during thermal degradation. The intensity of band that appears at $2927 \mathrm{~cm}^{-1}$ corresponding to aliphatic $\mathrm{CH}$ stretch decreased to a great extent or disappeared in the AC. The shifts in the bands suggest the formation of fused ring systems such as substituted naphthalene, anthracene or phenanthrene. Thus the extent of aromatic substitution decreases during thermal degradation and the AC formed a network of fused rings.

\section{SEM Analysis:-}

To study the effect of lignin degradation process, the surface morphology of the AC was recorded. SEM observations of the AC obtained from thermal degradation of lignin revealed its complex and porous surface texture. The SEM image shows a highly porous morphology of AC with pores of more or less different shapes and sizes and a variety of crevices on the external surface which shows smoother surface with irregular, heterogeneous and grainy surface. These may contribute to the relatively high surface area of the AC. The SEM image of prepared AC from lignin showed that the lignin particle has been softened, melted and diffused into the mass of matrix with number of 
pores on its surface. These vesicles, micropores and mesopores might have been the result of volatile gases released from the softened lignin matrix during carbonization.

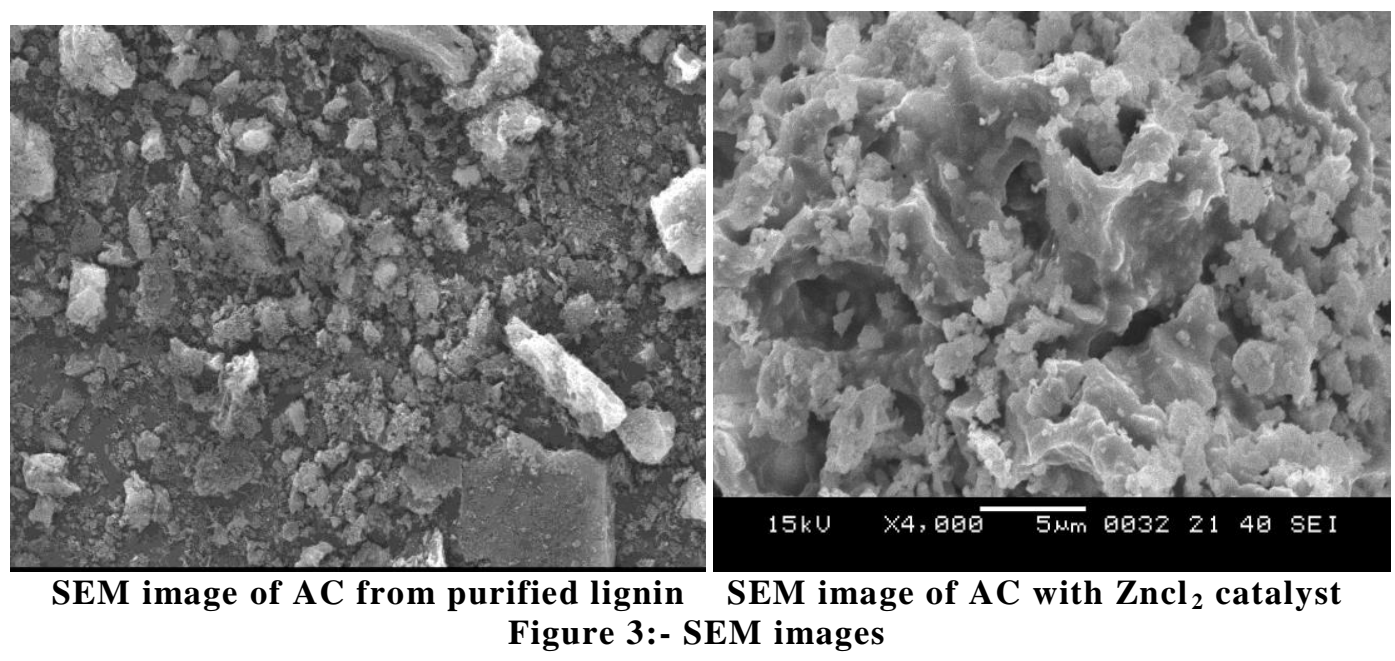

Researchers suggest that the mentioned pores represent active sites of the adsorption process. Moreover, remarkably porous material having a high specific surface area should be able to play an important role in phenol removal from aqueous solution.

\section{Surface Textural Properties:-}

The $\mathrm{N}_{2}$ adsorption isotherm at $-196^{\circ} \mathrm{C}$ of the $\mathrm{AC}$ obtained from thermal degradation of lignin was carried out. The surface area of the prepared $\mathrm{AC}$ obtained on thermal degradation at $500^{\circ} \mathrm{C}$ with the impregnation ratio of lignin to $\mathrm{ZnCl}_{2}$ catalyst as 1:1 was found to be $819.82 \mathrm{~m}^{2} / \mathrm{g}$. AC with $\mathrm{ZnCl}_{2}$ as activating agent has the surface area as large as those of commercial activated carbon. $\mathrm{ZnCl}_{2}$ worked as dehydration reagent and restricted the formation of tar and promoted the charring and aromatization of carbon upto carbonization temperature $500^{\circ} \mathrm{C}$. This can be the reason for the higher yield and more surface area of the $\mathrm{AC}$ prepared by $\mathrm{ZnCl}_{2}$ activation.

Optimization of various parameters for maximum uptake of Phenol on the coke obtained by thermal degradation of lignin:-

Optimization of adsorbent dose:-

The effect of adsorbent dose on the removal of phenol by AC was studied for the initial concentration. The uptake studies have been carried out by varying the adsorbent dose, ranging from 0.25 to $2 \mathrm{~g} / 100 \mathrm{ml}$ for the time interval of 60 mins. Table 3 shows the effect of adsorbent dosage on the removal of phenol by the AC obtained from industrial waste lignin. The maximum removal of phenol was obtained for the adsorbent dose $1 \mathrm{~g} / 100 \mathrm{ml}$. The $\%$ removal of phenol was $78.48 \%$. However it was observed that after this dose, there was no significant change in the $\%$ removal of phenol. It may be due to the availability of the exchangeable sites or surface area on the adsorbents. So $10 \mathrm{~g} / \mathrm{l}$ was considered as the optimum dose for the uptake studies. As the quantity of adsorbent increases, the number of adsorbent particles increases and more exchangeable sites are available, so more phenol is attached to the vacant sites.

Table 3:- Effect of adsorbent dose on removal of Phenol

\begin{tabular}{|c|c|c|}
\hline Sr. No. & Quantity of AC per 100 ml of phenol solution (g) & \% Uptake \\
\hline 1 & 0.25 & 58.24 \\
\hline 2 & 0.5 & 65.64 \\
\hline 3 & 0.75 & 70.12 \\
\hline 4 & 1 & 78.48 \\
\hline 5 & 1.25 & 83.74 \\
\hline 6 & 1.5 & 87.20 \\
\hline 7 & 2 & 91.47 \\
\hline
\end{tabular}




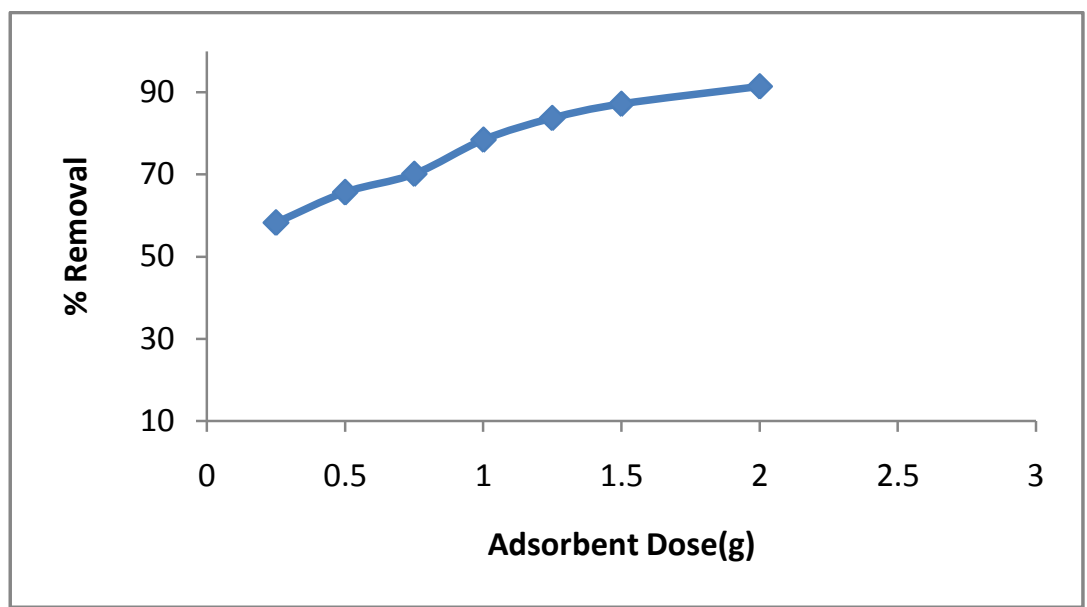

Figure 4:- Effect of adsorbent dose on removal of Phenol

\section{Effect of pH:-}

The uptake capacity is largely dependent on $\mathrm{pH}$ of aqueous solution The removal of phenol under similar conditions was studied at different $\mathrm{pH}$. The \% adsorption increases with $\mathrm{pH}$ to attain a maximum at $\mathrm{pH}$ 6-7. The effect of variation of $\mathrm{pH}$ on removal of phenol by the $\mathrm{AC}$ obtained from thermal degradation of industrial waste lignin in presence of $\mathrm{ZnCl}_{2}$, has been summarized below:

Table 4:- Effect of $\mathrm{pH}$ on removal of Phenol

\begin{tabular}{|c|c|c|}
\hline Sr. No. & pH & \% Uptake \\
\hline 1 & 2 & 42.32 \\
\hline 2 & 3 & 49.85 \\
\hline 3 & 4 & 51.26 \\
\hline 4 & 5 & 54.62 \\
\hline 5 & 6 & 59.8 \\
\hline 6 & 7 & 65.8 \\
\hline 7 & 8 & 67.61 \\
\hline 8 & 9 & 71.28 \\
\hline 9 & 10 & 74.13 \\
\hline
\end{tabular}

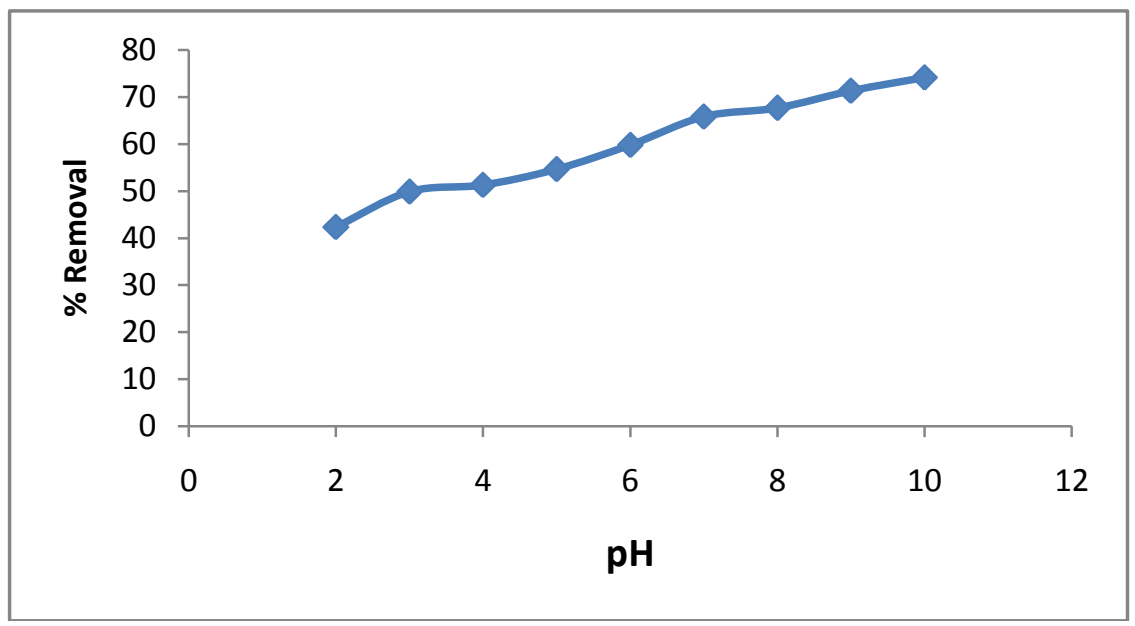

Figure 5:- Effect of $\mathrm{pH}$ on the removal of Phenol

Effect of contact time and initial phenol concentration:-

For a fixed concentration of phenol solution and a fixed adsorbent mass, the removal of phenol increased with increasing contact time. It was observed that the adsorption rate initially increased rapidly, and that the optimal 
removal efficiencies were reached within about 3 hrs: $80.43 \%$ for phenol. The removal efficiencies reached a steady value with increasing contact time after equilibrium had been reached. This may be due to the fact that initially all adsorbent sites were vacant, later the removal rate of phenol was not increased significantly resulted from saturation of adsorbent surfaces with phenol, it indicates the possible monolayer formation on the outer surface of adsorbent. Effect of contact time for removal of phenol is tabulated in Table 5.

Table 5:- Effect of contact time on removal of Phenol by AC

\begin{tabular}{|c|c|c|}
\hline Sr. No. & contact time (in hrs) & \% uptake \\
\hline 1 & 1 & 69.48 \\
\hline 2 & 2 & 74.55 \\
\hline 3 & 3 & 80.43 \\
\hline 4 & 4 & 84.14 \\
\hline 5 & 5 & 89.58 \\
\hline 6 & 6 & 93.8 \\
\hline
\end{tabular}

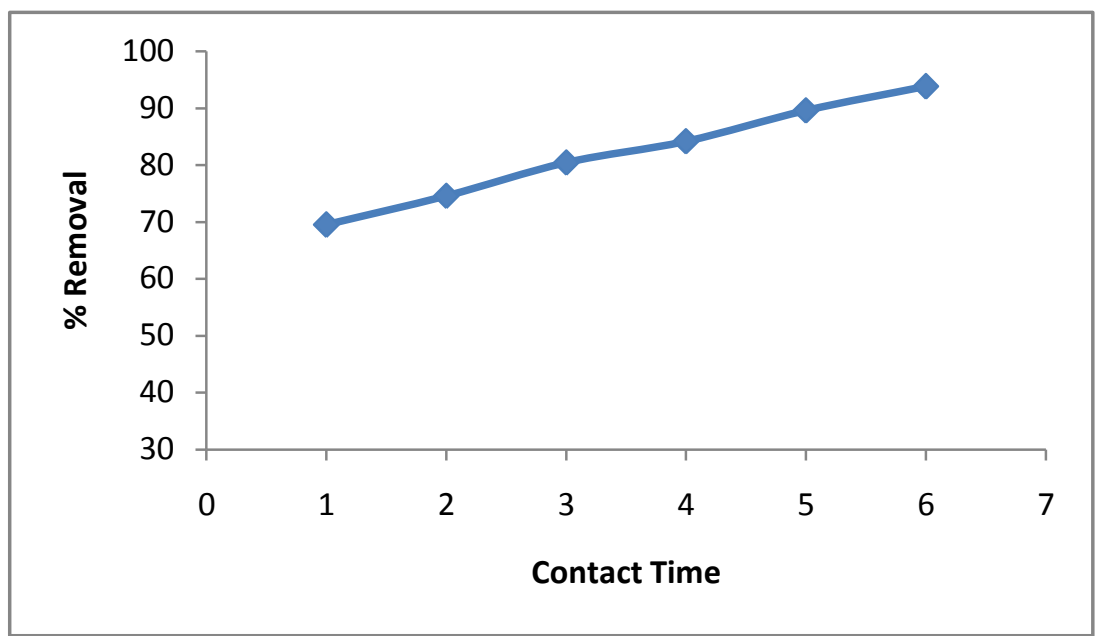

Figure 6:- Effect of contact time on removal of Phenol

\section{Adsorption isotherms for Phenol:-}

The analysis of equilibrium data for the adsorption of phenol on the AC obtained on degradation of industrial waste lignin was carried out with the Freundlich and Langmuir isotherm model. Figure 7 shows the adsorption isotherms of Freundlich model and Figure 8 shows the adsorption isotherms of Langmuir model.

The parameters of the two models were calculated and summarized from the plots of $1 / \mathrm{q}_{\mathrm{e}}$ versus $1 / \mathrm{Ce}$ and Log $\mathrm{q}_{\mathrm{e}}$ versus Log Ce (see Table 6). It can be observed that Langmuir isotherm model described the adsorption with higher $\mathrm{R}^{2}$ indicating the identical affinity for the adsorbate and no transmigration of the adsorbate on the surface of coke. The values of $1 / \mathrm{n}$ were discovered to be less than 1 which means the adsorption is favourable. From the Langmuir isotherm model, it has been observed that the adsorption capacity $\left(\theta^{0}\right)$ of the AC for phenol is $19.305 \mathrm{mg} / \mathrm{g}$.

The linear plots of $1 / q_{e}$ versus $1 / C_{e}$ suggests the applicability of Langmuir model, showing the formation of monolayer coverage of the adsorbate at the outer surface of the adsorbent. The essential characteristic of Langmuir isotherm is expressed in terms of dimensionless equilibrium parameter, $\mathrm{R}$. The values of $\mathrm{R}$ lie between 0 and 1 showing favorable adsorption of organic species on the adsorbent.

Table 6:- Freundlich and Langmuir Constants for Adsorption of Phenol.

\begin{tabular}{|l|l|l|l|l|l|l|l|}
\hline Sr. & Organic & \multicolumn{2}{|l|}{ Freundlich constants } & \multirow{2}{*}{$\mathbf{R}^{\mathbf{2}}$} & \multicolumn{2}{|l|}{ Langmuir constants } & $\mathbf{R}^{\mathbf{2}}$ \\
\cline { 3 - 4 } No & Species & $\mathbf{1 / n}$ & & $\mathbf{b}$ & $\boldsymbol{\theta}^{\mathbf{0}}$ & \\
\hline 1 & Phenol & 0.2835 & 7.7125 & 0.9201 & 0.3650 & 19.3050 & 0.9707 \\
\hline
\end{tabular}

The essential characteristic of Langmuir isotherm may be expressed in terms of dimensionless equilibrium parameter, the values of $\mathrm{R}$ for phenol lie between 0 and 1 showing favorable uptake of the dye on the adsorbent (see Table 7). 
Table 7:- Equilibrium parameter $(\mathrm{R})$ at different initial concentration of Phenol

\begin{tabular}{|c|c|c|}
\hline Sr. No. & Initial Concentration (mg/l) & Equilibrium parameter (R) \\
\hline 1. & 100 & 0.0519 \\
\hline 2. & 120 & 0.0436 \\
\hline 3. & 140 & 0.0376 \\
\hline 4. & 160 & 0.0331 \\
\hline 5. & 180 & 0.0295 \\
\hline 6. & 200 & 0.0266 \\
\hline
\end{tabular}

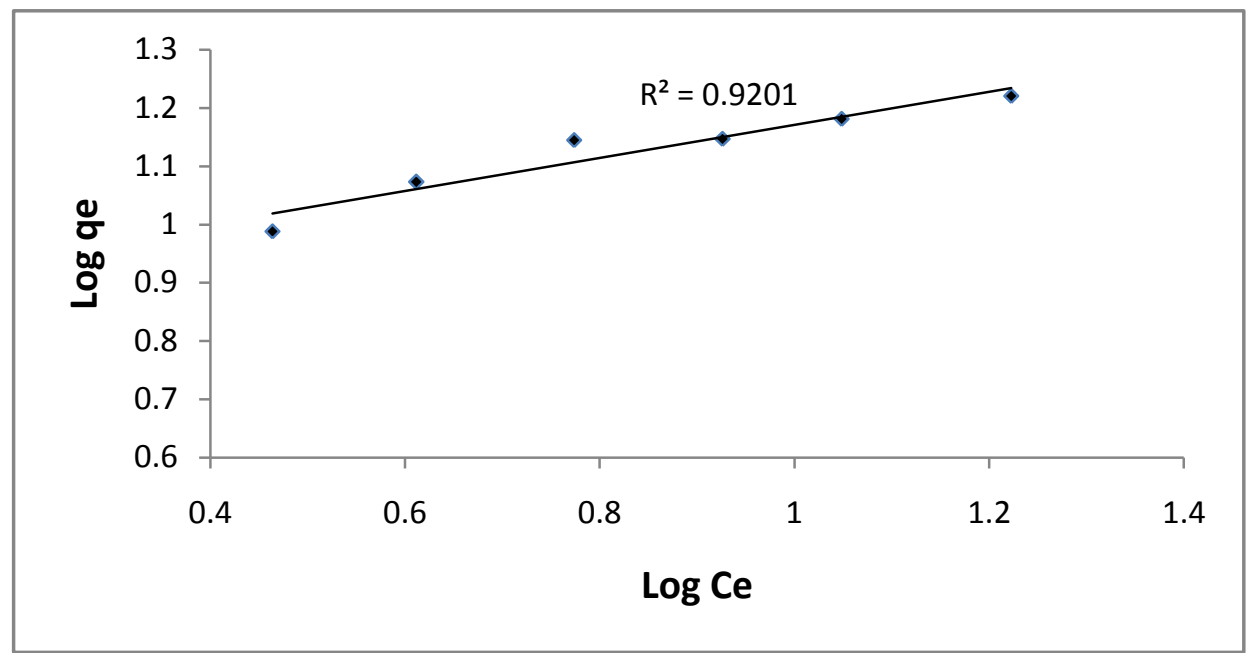

Figure 7:- Freundlich Isotherm of Phenol on AC

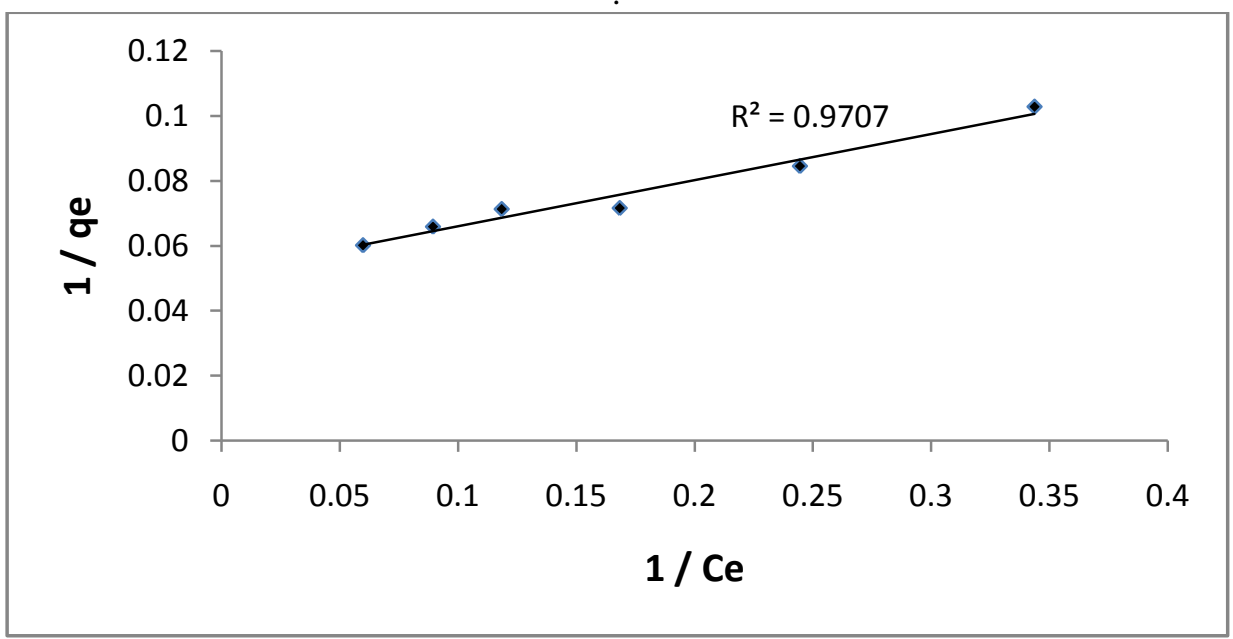

Figure 8:-. Langmuir Isotherm of Phenol on AC

Thus this study investigated the feasibility of lignin derived activated carbon as a new, low cost and efficient adsorbent for phenol adsorption. The chemical activation of lignin with $\mathrm{ZnCl}_{2}$ activating agent is a suitable method for the preparation of AC with high surface area.

\section{Conclusions:-}

Activated carbon obtained from industrial waste lignin can be successfully used as a low cost adsorbent for removal of phenol. On appropriate treatment, lignin has potential to become an effective and economical adsorbent for waste water treatment. Lignin can replace the expensive commercially available activated carbon for removal of phenol. Thus utilization of the lignin in this way is promising and minimizes the disposal problems and converts the waste into useful raw materials. 


\section{References:-}

1. Kennedy L J, Vijaya J.J, Kayalvizhi K, Sekaran G, 2007. "Adsorption of phenol from aqueous solutions using mesoporous carbon prepared by two-stage process". Chem. Eng. J. 132, 279-287.

2. Hameed and Rahman 2008. "Removal of phenol from aqueous solution by adsorption onto activated carbon prepared from biomass material" J. Hazardous Materials, 160. 2-3, 576-581

3. Calace, N., Nardi, E., Petronio, B. and Pietroletti, M.2002 "Adsorption of Phenols by Papermill Sludges" Environmental Pollution, 118, 315-319.

4. Subramanyam, B. and Das, A. 2009 "Linearized and Non-Linearized Isotherm Models Comparative Study on Adsorption of Aqueous Phenol Solution in Soil" International Journal Environmental Sciences \& Technology, 6, 633-640.

5. Gordon McKay, Andrew G. Sweeney, 1980, "Principles of dye removal from textile effluent" Water, Air and Soil pollution, 14, 1, 3-11.

6. Rao K. C. Krishnaiah K., \& Ashutosh 1994 "Colour removal from a dyestuff industry eft1uent using activated carbon" Indian Journal of Chemical Technology,1,13-19.

7. Tongpoothorn, W., Sriuttha, M., Homchan, P., Chanthai, S. and Ruangviriyachai, C.2011 "Preparation of Activated Carbon Derived from Jatropha curcas Fruit Shell by Simple Thermo-Chemical Activation and Characterization of Their Physico-Chemical Properties" Chemical Engineering Research and Design, 89, 335340 .

8. Mohd Din A. T., Hameed B.H., Ahmad A.L.2009 "Batch adsorption of phenol onto physiochemical-activated coconut shell’J. Hazardous Material, 30;161(2-3):1522-9.

9. Mohan $\mathrm{D}^{1}$, Pittman C.U. Jr, 2006, "Activated carbons and low cost adsorbents for remediation of tri- and hexavalent chromium from water". J Hazard Mater. 21;137(2)762-811.

10. Mohan D., Singh K. P., Singh V. K. Singh,2006 "Trivalent chromium removal from wastewater using low cost activated carbon derived from agricultural waste material and activated carbon fabric cloth". Journal of Hazardous Materials B135, 280-295

11. Atkinson, B.W., Bux, F., Kasan, H.C.,1998 "Considerations for application of biosorption technology to mediate metal-contaminated industrial effluent". Water SA, 24, 2, 129-135.

12. Lee, S. M., Davis, A. P. 2001, "Removal of cu(ii) and cd(ii) from aqueous solution by seafood processing waste sludge" Water Res., 35, 2, 534-540.

13. Mohan, D., Chander S.,2006, "Removal and recovery of metal ions from acid mine drainage using lignite-A low cost sorbent", Journal of Hazardous Materials B137 1545-1553.

14. Al-Asheh, S., Duvnjak, Z.,1997, "Sorption of cadmium and other heavy metals by pine bark"J. Hazardous Mater., 56,35-51.

15. McKay,G., Porter, J. F.,1997, “ Equilibrium Parameters for the Sorption of Copper, Cadmium and Zinc Ions onto Peat" Chem. Tech., Biotechnology,69, 3, 309-320.

16. Srivastava, S. K., Singh S.K., Sharma, A., 1994."Studies on the uptake of lead and zinc obtained from black liquor-a paper industry waste material" Environ. Techn., 15, 353-360..

17. Lalvani , S. B., Wiltowski, T.S., Murphy, D., \& Lalvani, L. S., 2010, "Metal Removal from Process Water by Lignin”Environm. Technology,18, 1163-1168.

18. Wieber, J., Kulik, F., Pethica, B.A., Zuman, P.,1988," Sorption on lignin, wood, cellulose, Copper(II), Zinc(II) ions, Colloidal. Surf.33, 141-152.

19. Mohan, D., Pittman C.U. Jr. Steele, P.H., 2006, "Single, Binaryand Multicomponent adsorption of Copper and Cadmium from aqueous solution on kraft lignin-a biosorbent”. J. Colloidal Interface Sci., 297. 489-504.

20. Crist, D.R., Crist, R. H., Martin, J.R., 2003, "A new process for toxic metal uptake by a kraft lignin" J. Chem. Tech. Biotechnology, 78, 199-202.

21. Belgin, K, Fatma T, Hakan D, Ilknur D,2008," , Liquid phase adsorption of phenol by activated carbon derived from Hazelnut Bagasse” J. Int. Environ. Applications \& Science, 3(5), 373-380

22. Kulkarni S, Patil S, Tapre R, Kadu S, 2011, "Studies on adsorption for Phenol removal by using activated carbon in batch and fluidized bed adsorption", Institute of Tech, 8-10,382-481.

23. Williams, P.T., Reed, A.R.,2006, " Development of activated carbon pore structure via physical and chemical activation of biomass fibre waste" Biomass Bioenergy, 30(2), 144-152.

24. Silverstein, R. M., Baster, C.G., Merrill, T.C.,1991, "Spectroscopic identification of organic compounds, $5^{\text {th }}$ edition, Wiley International", 158.

25. Kemp. W.,1998, Organic Spectrosopy, $2^{\text {nd }}$ edition, ELBS, Mcmillan Education Ltd, 44. 